\title{
VIVÊNCIAS, OLHARES E DESAFIOS DOS SUJEITOS DO PROEJA NO DESENVOLVIMENTO DO PROJETO INTEGRADOR
}

\author{
Samanta Lopes Maciel1, Edna Castro de Oliveira² \\ Pós-graduação Lato Sensu em Proeja, Instituto Federal do Espírito Santo \\ E-mail: samanta@ifes.edu.br, o liveiraedna@yahoo.com.br
}

\section{RESUMO}

Este artigo é um recorte do trabalho final do curso de Especialização Lato sensu do Programa Nacional de Integração da Educação Profissional com a Educação Básica na modalidade de Educação de Jovens e Adultos (Proeja) do Instituto Federal do Espírito Santo (Ifes) Campus Serra. Configura-se na tentativa de resgate das vivências, olhares e desafios dos sujeitos educandos do Curso Técnico Integrado de Segurança do Trabalho do Proeja do Ifes Campus Vitória produzidos no desenvolvimento do Projeto Integrador. Nele, tenta-se identificar elementos que têm influído nesse processo, bem como as principais dificuldades encontradas pelos alunos em suas trajetórias no Proeja. Busca-se, ainda, responder se o Projeto Integrador pode ser considerado uma possibilidade de reconhecimento dos saberes dos sujeitos educandos do Proeja. Adotou-se como metodologia a pesquisa qualitativa, e a técnica de coleta utilizada foi o grupo focal, além da realização de um questionário cujos objetivos foram traçar o perfil dos sujeitos e coletar a opinião de pedagogas e professores. Os dados levantados possibilitaram concluir que há dificuldades de acesso, de falas e de posturas dentro da instituição, que refletem o processo de elitização da escola e que precisam ser superadas. Os dados também apontam a possibilidade de envolvimento e reconhecimento dos saberes dos educandos no percurso do Projeto Integrador, elemento considerado indispensável ao processo educativo.

Palavras-chave: Proeja. Direito à educação. Projeto Integrador. Sujeitos e saberes.

\section{INTRODUÇÃO}

O percurso da Educação de Jovens e Adultos (EJA) no Instituto Federal do Espírito Santo (Ifes) no Campus Vitória teve seu início antes do Decreto $n^{\circ}$ 5478/2005 que instituiu o Programa Nacional de Integração da Educação Profissional com a Educação Básica na modalidade de Educação de Jovens e Adultos (Proeja). A oferta ocorre desde o ano de 2001, por meio de um projeto ousado à época, intitulado Ensino Médio Para Jovens e Adultos Trabalhadores (EMJAT). Pode-se dizer que o Ifes já tinha os olhos voltados para a inclusão, conforme prescreve a legislação brasileira. Nessa caminhada, o grande desafio da EJA nesta instituição concentrou-se no rompimento do imaginário cristalizado de que essa modalidade poderia ameaçar a tradição de excelência do instituto (CEZARINO; OLIVEIRA, 2008). Para alcançar o objetivo da inclusão, algumas estratégias metodológicas foram adotadas na formulação dos Cursos Técnicos Integrados ofertados via Proeja. Entre elas, destaca-se o Projeto Integrador ${ }^{3}$, instrumento que se coloca como possibilidade de contextualização das aprendizagens dos educandos, apostando no diálogo entre as disciplinas. Esta estratégia metodológica apresenta-se

\footnotetext{
${ }^{1}$ Pedagoga do Ifes campus São Mateus. Especialista em Educação Profissional na modalidade EJA e em Gestão Educacional.

${ }^{2}$ Doutora em Educação. Professora Adjunta do Centro de Educação e do Programa de Pós Graduação em Educação da UFES, coordenadora geral do grupo de pesquisa PROEJA/CAPES/SETEC/ES.

${ }^{3}$ Esse projeto é desenvolvido na disciplina intitulada Metodologia da Pesquisa e se insere nos módulos II, III e IV dos Cursos.
} 
para os alunos como uma forma de tornar a aprendizagem significativa, uma vez que as temáticas desenvolvidas emergem do cotidiano dos alunos.

Desta maneira, a problemática principal deste trabalho configura-se numa tentativa de responder, ou fazer emergir, questões como as vivências, os olhares e os desafios dos sujeitos educandos do Curso Técnico Integrado de Segurança do Trabalho/Proeja/Ifes, Campus Vitória, produzidas no desenvolvimento do Projeto Integrador.

A ideia do trabalho com Projeto Integrador tem seu início na experiência com a metodologia de projetos ${ }^{4}$, iniciada no EMJAT, a partir da adoção dos eixos temáticos para desenvolvimento das aulas. Segundo Ferreira et al., tinha como objetivo principal "[...] sistematizar e integrar as contribuições das demais disciplinas para o projeto e, simultaneamente, orientar os alunos quanto aos passos da construção científica do projeto que deveria ter a interdisciplinaridade como princípio" (2007, p.11).

\section{SUJEITOS, SABERES E DIRETO NA EDUCAÇÃO DE JOVENS E ADULTOS}

Como suporte teórico, este estudo apóia-se nos ensinamentos de Arroyo (2004) para fundamentar a concepção do direito do trabalhador à educação. Embora a maioria dos participantes dessa investigação seja de donas de casa, aqui essas mulheres adultas serão consideradas trabalhadoras, uma vez que o trabalho é entendido não apenas como emprego formal, mas toda aquela atividade que produz a existência humana, que forma o ser enquanto sujeito e o caracteriza enquanto pertencente a uma determinada classe.

Segundo Arroyo (2004), não é polêmica para nenhum governo o reconhecimento da necessidade da democratização da educação formal para os trabalhadores, facilmente constatada pela expansão da escolarização. Porém, esta vem ocorrendo sem permitir que os trabalhadores alcancem a educaçãoformação e funcionando como uma forma de reprimir os saberes, a organização e a constituição da identidade da classe trabalhadora. Essa relação instrução $x$ formação foi denominada por Arroyo de binômio libertar-reprimir, que tem caracterizado a oferta educacional em vários países, mais precisamente no Brasil, o que retoma a idéia de uma "visão depreciativa para com o povo comum e com os trabalhadores" (2004, p.74).

Ainda, segundo este autor, a plenitude do alcance do direito à educação não se dá apenas com a garantia do acesso à escola, pois o que está em jogo não é apenas o domínio dos instrumentos básicos que a escola transmite como "leitura, escrita, noções de ciências, contas", mas, sim, a negação do direito das classes trabalhadoras à educação e à formação da cultura e da identidade enquanto classe. Tenta-se assim reduzir o direito à educação, a entrada e a permanência do trabalhador durante alguns anos na escola, negando que os trabalhadores sejam produtores de saber e de cultura (ARROYO, 2004, p. 80).

Segundo Paiva (2006), o direito à educação de jovens e adultos no "Pós-Hamburgo" adquire duas vertentes:

a primeira, a da escolarização, assegurando o direito à educação básica a todos, independentemente da idade, e considerando a educação como direito humano fundamental; a segunda, a da educação continuada, como exigência do aprender por toda a vida [...] (PAIVA, 2006, p.522).

\footnotetext{
${ }^{4}$ Raggi define a proposta metodológica adotada no EMJAT/PROEJA, através do seguinte conceito: "conjunto de técnicas e processos pedagógicos usados para integrar as diversas áreas do saber e construir conhecimentos centrados em problemas reais, na busca de solução para os mesmos, por meio de pesquisas científicas e da obtenção de um produto concreto" (RAGGI, 2008, p. 96).
} 
Para a autora, é no aprender ao longo da vida que se encontra o verdadeiro sentido da EJA, uma vez que é via processos sociais que os sujeitos se humanizam. Assim, a concepção de direito à educação está intimamente ligada ao aprender ao longo da vida.

A concepção de direito à educação enquanto direito à instrução ou ao acesso a escola, implica reducionismo do conceito de direito à educação, já que esse se refere a um processo social mais amplo que engloba a valorização do saber, da educação e da cultura, produzidos pelas classes sociais no seu dia a dia (ARROYO, 2004).

No que se refere ao papel do Estado na garantia desse direito, a concretização da EJA e a reconfiguração sobre sua concepção de direito à educação, implica uma mudança do olhar por parte desse sobre os sujeitos que dela fazem parte, reconhecendo que esses jovens e adultos são "sujeitos de direitos e sujeitos de deveres do Estado" (ARROYO, 2005, p. 26).

A educação deve ser assumida pelo Estado como um direito que sempre foi negado para os mesmos grupos sociais, raciais e culturais e concebida como uma política afirmativa, como uma dívida histórica para com setores que foram marginalizados do processo educacional.

Para Oliveira (2008), o sujeito adulto que frequenta os bancos da EJA geralmente advém da zona rural e é proveniente de áreas empobrecidas, que chega à metrópole em busca de melhores condições de vida; são sujeitos que possuem baixo nível de instrução escolar e buscam a escola tardiamente. Os jovens da EJA, assim como os adultos, também são pessoas excluídas da escola, geralmente incorporados aos cursos supletivos em fases mais adiantadas de escolaridade (OLIVEIRA, 2008, p. 16).

Segundo essa autora, a reflexão sobre esses sujeitos de conhecimento requer transitar por três campos, que contribuem para a definição de quem são esses sujeitos jovens e adultos. Primeiramente, é necessário reconhecer sua "condição de não-criança", já que se trata de uma pessoa adulta, inserida no mundo do trabalho e das relações interpessoais, diferentemente da forma como o fazem crianças e adolescentes. "Traz consigo uma história mais longa de experiências" e conhecimentos sobre o mundo, acumulados ao longo da vida e vê o cotidiano a partir de um olhar diferenciado, embasado em suas vivências e experiências (OLIVEIRA, 2008, p.18). Além disso, esse público possui uma especificidade, porquanto se encontra na condição de "excluído(s) da escola" regular e, nesse aspecto, esbarra-se nos currículos e métodos adotados para esse público da EJA que incorrem em práticas escolares de infantilização, uso de expressões que fazem com que a sua condição de excluído da escola regular se torne potencializadora da exclusão escolar tardia (OLIVEIRA, 2008, p. 20). Por último, a eminente autora fala sobre a "condição de membro de determinados grupos culturais" com especificidades que devem ser examinadas e relacionadas aos "[...] aspectos que os definem como um grupo relativamente homogêneo no interior da diversidade de grupos culturais da sociedade contemporânea [...]" (OLIVEIRA, 2008, p. 22).

O campo da definição de quem são esses sujeitos jovens e adultos vem passando por uma reconfiguração que aponta para a superação de uma visão de que se tratam de pessoas que não tiveram acesso à educação na infância ou na adolescência, ou que foram excluídas, ou que se evadiram do ensino fundamental, sendo que nesta formatação, o direito à educação resolver-se-ia simplesmente na oferta de uma "segunda oportunidade de escolarização" (ARROYO, 2005, p. 23).

À medida que a visão de oferta de instrução como sinônimo de direito é superada, a possibilidade sobre a definição de quem são esses sujeitos se amplia:

Um novo olhar deverá ser construído, que os reconheçam como jovens e adultos em tempos e percursos de jovens e adultos. Percursos sociais onde se revelam os limites e possibilidades de ser reconhecidos como sujeitos dos direitos humanos (ARROYO, 2005, p. 23). 
Assim, tratam-se de sujeitos em um tempo próprio, que portam diversas trajetórias, experiências, histórias de vida que devem ser reconhecidas e integradas ao processo educativo no seu percurso escolar. Ou seja, demandam a valorização de seus saberes e a oferta de uma demanda educacional que corresponda a sua condição de jovem e/ou adulto.

Paralelamente, esses sujeitos se formam e produzem sua existência no dia a dia, na luta cotidiana em busca da sobrevivência, nas comunidades em que estão inseridos, nos trabalhos, na Igreja, no sindicato, nos movimentos, na família etc. Como afirma Arroyo (2006, p. 25): "as trajetórias sociais e escolares truncadas não significam sua paralisação nos tensos processos de sua formação mental, ética, identitária, cultural, social e política". Esses sujeitos portam conhecimentos e saberes, sociais, historicamente produzidos e acumulados em suas trajetórias de vidas.

\section{A PESQUISA E OS SUJEITOS NELA ENVOLVIDOS}

Para exequibilidade deste trabalho, optou-se como metodologia a pesquisa qualitativa e considerouse importante utilizar como técnica de coleta de dados ${ }^{5}$ a realização de um grupo focal que permitisse contemplar aspectos subjetivos e objetivos relacionados ao fim deste estudo.

A técnica utilizada apresenta vantagens por fazer emergir opiniões menos individuais, além de possibilitar o confronto de opiniões diretas sobre determinado objeto de estudo, oportunizando a emergência de fatores impossíveis de serem percebidos em técnicas que ouvem o indivíduo de forma isolada, sendo apropriada para estudos que buscam entender atitudes, preferências, necessidades e sentimentos (GONDIM, 2010).

Além dos estudantes, contribuíram também para coleta de dados três professores que ministraram a disciplina de Metodologia nos cursos do Proeja e três pedagogas que atuam nessa modalidade, com a finalidade de auxiliar na leitura sobre o desenvolvimento do Projeto Integrador nesse curso. A participação desse grupo foi fundamental para sustentar algumas de nossas conclusões.

Como lócus de desenvolvimento dessa pesquisa foi escolhida a turma 2007/01, do Curso Técnico Integrado de Segurança do Trabalho/Proeja/Ifes Campus Vitória ${ }^{6}$. Dos sete participantes do grupo focal, todas eram mulheres, em sua maioria, casadas, acima dos 45 anos; duas participantes se situam entre 30 e 31 anos e uma com 25 anos. São donas de casa, também em sua maioria. Apenas uma trabalha fora (hospital).

Sobre a questão da ocupação das mulheres, Ferreira (2007) em sua pesquisa sobre escolarização e gênero feminino, ao traçar o perfil das alunas participantes encontrou o mesmo perfil de sujeitos:

[...] Todas exercem atualmente a função de dona de casa, sem qualquer remuneração. É notório que as dificuldades históricas de acesso à instrução e à educação formal representaram para as mulheres uma completa falta de qualificação profissional fora do lar, o que condiciona sua participação no mundo do trabalho. Assim os afazeres domésticos sempre foram sua obrigação e sua responsabilidade (FERREIRA, 2007, p. 56).

A maioria é originária da escola pública e, ao ingressarem no PROEJA, quatro das sete haviam concluído o Ensino Fundamental; uma estava cursando o Ensino Médio e duas já haviam concluído. Destaca-se que na realização do grupo focal ficou explícito que todas elas traziam, no percurso

\footnotetext{
${ }^{5}$ Aplicou-se também um questionário para traçar o perfil dos sujeitos educandos envolvidos.

${ }^{6}$ Optou-se por abordar os alunos do último módulo do Curso, justificando-o pelo fato desses estarem em fase de conclusão e por se julgar que poderiam fornecer os elementos para o cumprimento do objetivo principal desse estudo.
} 
formativo, a experiência oriunda de classes de supletivo ${ }^{7}$. Além disso, ao procurar o Proeja, todas as alunas buscavam a qualificação para inserção no mercado de trabalho, porém o objetivo inicial foi alterado no percurso, e as mesmas fizeram questão de frisar que o objetivo passou a ser ingressar na universidade.

O grupo participante deste trabalho integra o público que constitui os sujeitos da EJA. São mulheres adultas com trajetórias escolares marcadas pela descontinuidade e pela negação de direitos, que têm sofrido historicamente a exclusão, que retornam à escola e veem o Proeja para além da possibilidade de qualificação profissional:

\begin{abstract}
Trata-se de um jovem ou adulto que historicamente vem sendo excluído, quer pela impossibilidade de acesso à escolarização, quer pela sua expulsão da educação regular ou mesmo da supletiva pela necessidade de retornar aos estudos. Não é só o aluno adulto, mas também o adolescente; não é só o inserido no mercado de trabalho, mas o que ainda espera nele ingressar; não mais o que vê a necessidade de um diploma para manter sua situação profissional, mas o que espera chegar ao ensino médio ou a universidade para ascender social e profissionalmente (DOCUMENTO FINAL DO SEMINÁRIO DE EDUCAÇÃO DE JOVENS E ADULTOS, NATAL, RN, 1996, p. 19).
\end{abstract}

\title{
OS DADOS: O PERCURSO NO PROEJA/IFES CAMPUS VITÓRIA: VIVÊNCIAS, OLHARES E DESAFIOS
}

Iniciado o grupo focal, tentou-se identificar as motivações que levaram as alunas a procurarem pelo curso, assim, as falas coletadas giraram predominantemente em torno de duas motivações principais: a procura por ampliar seus conhecimentos e o ingresso em uma escola de qualidade para ajudá-las a se inserir no mercado de trabalho, conforme a fala a seguir:

Na época que eu parei de estudar eu não completei, [...] só até a oitava série né, no ensino fundamental. Então eu não tinha o ensino médio né. Então fica difícil de conseguir um emprego, com salário melhor. Então eu voltei a estudar pra completar o ensino médio, e também adquirir um curso técnico (ALUNA B).

A partir dos depoimentos, pode-se inferir que ao procurarem o Curso Técnico Integrado de Segurança do Trabalho do Proeja, essas alunas, mesmo que não seja de forma planejada e deliberada, buscam um direito que em outro momento lhes foi negado: a educação de qualidade. Isso confirma o que denuncia Arroyo (2005, p.28): "Teimar em reduzir direitos a favores, à assistência, à suplência, ou a ações emergenciais é ignorar os avanços na construção social dos direitos entre eles à educação de jovens e adultos [...]".

Este movimento leva-nos à reflexão de que os sujeitos da EJA historicamente têm sido vítimas da desigualdade social e educacional que provoca sua exclusão e negação de direitos básicos, demandando por parte do Estado formulação de políticas apropriadas de forma a promover a "inserção dos mesmos no usufruto dos bens culturais a que todos devem ter acesso, dentre eles a educação" (CEZARINO e OLIVEIRA, 2008, p. 02).

Embora os relatos apontassem para trajetórias de vidas difíceis, chama atenção a simpatia que as alunas demonstraram quando retornaram ao passado para relembrarem suas histórias e os

\footnotetext{
${ }^{7}$ As alunas participantes do grupo focal tiveram, em boa parte de seu percurso de escolarização, a oferta via supletivo, sendo, assim, marcadas pelo ensino de baixa qualidade cujos currículos são inadequados ao público da EJA e que, muitas vezes, visa exclusivamente à conferência de certificação. Além disso, essas mulheres carregam a marca da descontinuidade.
} 
caminhos que percorreram até chegar ao Ifes. Assim não se poderia deixar de acrescentar o seguinte relato da aluna, feito quando ela soube que tinha sido aprovada no processo seletivo:

[...] até que um dia eu vi PROEJA no jornal, pra jovens e adultos no CEFETES, que é isso gente, eu não sabia como entrar eu não sabia como fazer, eu queria entrar no CEFETES, mas não sabia como... aí consegui passar, pra mim foi.... a realização do meu sonho e a minha vida mudou (ALUNA F).

Essas falas revelam o primeiro desafio encontrado pelos sujeitos do Proeja, uma situação a ser superada: o processo de elitização que afastou a instituição das classes sociais menos favorecidas. Nas falas que se seguiram àquela, surgiram outros relatos: "eu sempre passava aqui na frente, mas nem sabia que aqui era uma escola" (ALUNA B); "a comunidade aqui em volta, nem sabe que pode estudar aqui, nem sabem que aqui tem um ensino que é pra eles (se referindo ao Proeja)" (ALUNA C); $e$ "tem gente que pensa que eu pago pra estudar aqui, eles me perguntam quanto eu pago" (ALUNA D).

As falas provocam indignação. Elas refletem um quadro de negação do direito das pessoas jovens e adultas ao acesso a uma educação de qualidade, como afirma Arroyo (2005, p. 30): "Trata-se de trajetórias coletivas de negação de direitos, de exclusão e marginalização; consequentemente a EJA tem de se caracterizar como uma política afirmativa de direitos de coletivos sociais, historicamente negados" (2005, p. 30).

Esses depoimentos traduzem uma realidade dolorosa de que o Ifes ainda é uma possibilidade distante para os jovens e adultos da EJA, conforme sugere Freitas (2010, p.62):

[...] os dados encontrados já dão indícios que podem apontar para uma perspectiva de uma escola que prescritamente sempre esteve aberta a todos, mas que, durante muito tempo, permaneceu "elitizada" e, na prática, fechada ao alunado oriundo de classes populares.

É importante ainda acrescentar a discussão de como tem sido feito o processo de divulgação dos cursos ofertados ao público Proeja. Ela se dá via edital, apenas pelo sítio da instituição, muitas vezes inacessível à camada alvo do Programa, influenciando sobre os problemas de acesso. $O$ trabalho monográfico de Silva (2007) sobre a temática do acesso sinaliza que o processo seletivo, tanto do Ifes quanto da Universidade Federal do Espírito Santo (UFES), tornou-se inacessível para as camadas populares, refletindo um processo de distanciamento da sociedade dessas instituições. Para ele, os elementos que têm dificultado o acesso seriam: elitização da instituição, meios de divulgação ineficazes, valor da taxa de inscrição. E constata que "[...] os meios de divulgação, até então utilizados, como: edital, rádio, televisão, e jornal não demonstram que seja atendida a dimensão que precisamos ao PROEJA [...]" (2007, p. 46).

No segundo momento, tentou-se identificar os principais desafios enfrentados pelos alunos ingressantes no Proeja e foi relatado que as alunas, inicialmente, sentiram-se abraçadas pela instituição: "tudo de bom" (ALUNA E), "nem importava se era Proeja" (ALUNA A). Afirmaram ainda que a coordenação do Proeja sempre esteve aberta às reclamações e às solicitações. Porém, no contexto do debate, as falas apontaram para um segundo desafio enfrentado principalmente pelas alunas mais velhas: a questão da idade. Elas relataram que pelo fato de serem donas de casa, "mais de idade" sentiram-se mais excluídas em alguns momentos, principalmente na sala de aula. Segundo elas "os professores sempre atendiam as mais novinhas, sempre estavam perto delas". Desta maneira, a superação ou o enfrentamento do preconceito geracional, colocou-se como desafio a ser superado por essas mulheres. 
Nota-se um duplo processo de exclusão: se outrora as alunas foram excluídas da escola pela vida, agora serão novamente excluídas pelos professores, que ao formarem uma imagem do aluno perfeito, aquele que aprende, que tem a idade referente ao nível de escolarização deixam de lado os que são prejulgados como incapazes de aprender. Ou talvez esta postura, por parte do professor, seja apenas uma forma discreta de dizer ao aluno Proeja que aquele lugar não é seu, como discute Oliveira (2008), em estudo monográfico sobre o não-lugar dos alunos do Proeja no Ifes:

[...] o educador como principal componente desse processo, ao longo dos anos, tem garantido um importante papel que interfere diretamente no espaço que afirma o "não-lugar" e o "não-pertencimento" do grupo a ser pesquisado (OLIVEIRA, 2008, p. 14).

O terceiro desafio elencado pelas alunas consiste no preconceito por parte de alguns professores, principalmente os substitutos (em regime de contratação temporária), que chegaram a proferir falas como "aluno dez lá por aqui é oito, e quem é médio lá, fora, aqui não fica"; "aqui ninguém passa a mão na cabeça de aluno"; "vocês podem falar o que quiser, daqui a dois anos eu tô fora, quando chegar a mim eu não estou mais aqui" (ALUNA A, reproduzindo fala de professores). Essas posturas, além de refletir o problema estrutural da formação de professores no Brasil, contribuem para uma educação desumanizadora, a serviço da opressão (FREIRE, 2003).

Para Oliveira (2001), os usos de certas expressões colaboram para que a condição do aluno da EJA, de excluído da escola regular em outro momento, torne-se potencializadora de uma nova exclusão escolar.

Sobre o processo de inclusão dos educandos do Proeja, SILVA (2007, p. 34), reflete que "o processo de inclusão é gradativo e marcado por adversidades ocasionadas pela falta de habilidade dos atores para atuar com o Proeja e pela visão predominante e viciada de uma educação tradicional, elitista e conservadora."

Nos relatos das alunas, captaram-se falas que apontam o estranhamento com que foram recebidas pelos alunos do Ensino Médio Regular ${ }^{8}$. Em relato, a Aluna B afirmou ter ouvido de um desses alunos a frase "a limpeza agora usa o mesmo uniforme dos alunos?" o que demonstra que não foram reconhecidos como sujeitos de direito nem pelos "colegas" de escola. A postura dos estudantes adolescentes esbarra na necessidade de reconhecimento do público da EJA na "condição de nãocriança", sendo pessoas adultas, que estão inseridas no mundo do trabalho e das relações interpessoais, diferentemente da forma como o fazem os adolescentes que os estranharam (OLIVEIRA, 2001, p. 18).

Mais uma vez esbarra-se na discussão sobre o lugar dos estudantes do Proeja no Ifes Campus Vitória. Além de terem seu lugar negado pelos professores, agora também o tem negado pelos colegas de instituição. Sobre este elemento reflete Oliveira (2008. p. 36):

Dessa forma teremos um sujeito Proeja, inserido num contexto em que a experiência do não-lugar se estabelece como estrutura na constituição de uma identidade, que não identifica, que não reconhece o pertencimento de grupo, mas que segrega e, ao mesmo tempo, consolida o "não-lugar" como lugar comum.

O quarto desafio diz respeito ao uso dos serviços e espaços oferecidos pela instituição, que reforçam a ideia de que a escola é o espaço para jovens do Ensino Médio Regular, dentro de uma faixa etária determinada e esperada, e de uma determinada classe social. Uma das alunas, recém-ingressa

\footnotetext{
${ }^{8}$ Entende-se por alunos do Ensino Médio Regular todos aqueles alunos dentro da faixa etária esperada para essa etapa de ensino (adolescentes de 13 a 16 , ou 17 anos).
} 
procurou, com mais uma colega, pelo serviço de academia. A intenção era que pudessem frequentar as aulas, porém o que ocorreu foi a decepção, de acordo com a fala da aluna: [...] fomos muito mal recebidas, parecia que a gente tava querendo roubar algo. Precisa de ver a menina como tratou a gente. Eu pensei que eu poderia usar a academia, que nem os outros alunos, mas até desisti (ALUNA $\mathrm{G)}$.

É importante apontar a contradição descrita por Arroyo (2004) entre direito e educação no seu sentido mais amplo e direito à educação enquanto instrução, na medida em que essas alunas são privadas de vivenciar todos os espaços do Ifes em sua plenitude, sendo discriminadas pelos professores, alunos e demais servidores. Observa-se que em determinados espaços da instituição o que vem se garantindo é a concepção do direito à educação restrita a instrução. Sobre a inclusão desses sujeitos, Oliveira (2008), reflete que:

\footnotetext{
Desde sua criação, o PROEJA vem introduzindo no CEFETES - Vitória, um novo público, cujo papel elementar é de compor um espaço democrático dentro de uma instituição federal. Esse novo sujeito, ao contrário do que o programa sugere, encontra muitas dificuldades para se inserir no contexto a ele oferecido. Daí o interesse em entendê-lo, já que na maioria das vezes, sobrevive aos catastróficos planos institucionais (OLIVEIRA, 2008, p. 15).
}

Embora a instituição esteja aberta a entrada das classes menos favorecidas, por meio do Proeja, nota-se que ela não rompeu internamente com os paradigmas construídos historicamente (de espaço reservado para um seleto grupo de estudantes que já vêm da educação básica, não apresentam dificuldades de aprendizagem, geralmente "os melhores da turma"), fato esse comprovado pelos momentos de negação de direito (sofridos pelas estudantes do Proeja), refletidos nas posturas dos professores, dos alunos dos cursos que não são Proeja, da instituição e dos servidores. Essas posturas demonstraram o que Arroyo denominaria de "visão depreciativa para com o povo" (2004, p. 74).

O quinto desafio, analisado como um ponto negativo pelas alunas, refere-se ao fato das turmas serem completadas, no quinto módulo, com alunos que não eram de cursos do Proeja, ou seja, que já possuíam o Ensino Médio e não tinham o perfil dos educando da modalidade da EJA, que se juntaram a esse grupo apenas para concluir o ensino técnico. Na verdade, este elemento aponta uma contradição, já que neste momento o aluno do Proeja deixa de ter uma oferta apropriada à natureza do curso, não sendo consideradas aí as necessidades e expectativas do público a quem se destina.

\section{OS DADOS: VIVÊNCIAS, OLHARES E DESAFIOS NO DESENVOLVIMENTO DO PROJETO INTEGRADOR}

No terceiro momento da realização do grupo focal, passou-se a conversar sobre a realização do Projeto Integrador. Junto com as alunas fez-se um resgate das temáticas que foram desenvolvidas dentro do Projeto. O grupo avaliou o desenvolvimento do Projeto Integrador como um dos momentos mais importantes do Curso. De acordo com o seguinte relato, constatou-se que o mesmo representa um momento muito rico: [...] quando que eu ia imaginar, que uma ideia que foi eu que dei, poderia se transformar numa coisa tão grande, e que pudesse ajudar a outras pessoas (ALUNA A, sobre o Projeto Uso da Voz no Magistério).

A frase expressa a reflexão da aluna sobre o reconhecimento de seu saber, revelando ainda que sentem-se valorizadas ao verem "suas ideias" sendo incorporadas ao desenvolvimento do Projeto. A fala da Aluna A, reflete um ponto importante da realização do Projeto, que vai ao encontro da reflexão levantada por RAGGI (2008) sobre o Projeto Integrador: 
[...] mesmo com todas as limitações que apresenta quanto às dimensões epistemológicas, ontológicas e pedagógicas, ainda assim tem potencial para realizar uma educação consistente para as classes populares do país, visando romper a lógica educativa dos grupos dominantes que desconsideram as práticas, saberes, costumes, artes e os modos de vida da classe trabalhadora (RAGGI, 2008, p. 54).

O Projeto sobre Uso da Voz no Magistério, desenvolvido por essa turma, extrapolou os muros do Ifes e foi apresentado em escolas públicas de Vitória. Através desse Projeto e com o apoio do professor do curso, os alunos realizaram oficinas com os professores do próprio Instituto, desenvolvendo atividades de respiração, exercícios para a voz, conscientização sobre o uso correto da voz. A culminação do projeto deu-se por meio da realização de um teatro (relato das alunas no grupo focal). Neste processo, as alunas apontaram como uma das dificuldades encontradas o ato de falar em público, pois alguns alunos tinham "muita vergonha" e afirmaram que o Projeto Integrador "ajudou muito nessa parte", demonstrando assim uma postura reflexiva sobres suas dificuldades e o processo de aprendizagem:

Com relação à inserção em situações de aprendizagem, essas peculiaridades da etapa da vida em que se encontra o adulto fazem com que ele traga consigo diferentes habilidades e dificuldades, e provavelmente, maior capacidade de reflexão sobre o conhecimento e sobre seus próprios processos de aprendizagem (OLIVEIRA, 2008, p. 18).

O acompanhamento da execução do Projeto Integrador permitiu constatar então que esse auxilia no desenvolvimento da habilidade de falar em público, na superação da timidez que, futuramente, pode evitar problemas profissionais, além de trabalhar com a postura do aluno, com o senso de liderança, e com a autonomia.

Estes aspectos também foram apontados no trabalho realizado por Raggi (2008) e por membros da equipe que trabalhou com a disciplina de metodologia no Proeja: [...] Minha experiência mostrou que o avanço alcançado pelos alunos, no que diz respeito à autonomia, é significativo e merece maior atenção (PROFESSOR A). Outro profissional destaca:

[...] considerando que o processo educativo envolve as dimensões, cognitiva, afetiva e atitudinal, pode-se afirmar, a partir de experiência vivenciada com os alunos do PROEJA, o papel fundamental que o projeto exerce na formação e no crescimento pessoal e profissional desses alunos (PEDAGOGA A).

Porém, cabe ressaltar que o trabalho com o projeto integrador, embora contribua para formação de atitudes e valores nos educandos, mostra uma face contraditória que é a forma como alguns alunos e professores encararam o trabalho. Muitos desses se mostram resistentes no diálogo entre as disciplinas, refletindo a dificuldade de romper com o imaginário da educação tradicional:

Era totalmente perceptível a evolução do aluno, no que tange a autonomia e algumas habilidades (falar em público, buscar informações, liderança, senso crítico etc.). No entanto, é importante frisar, isso era limitado a alguns, exatamente aqueles que se empenhavam. Isso é algo relevante, pois evidencia que o projeto integrador não era considerado relevante - como proposta de trabalho pedagógico - para todos. Não é só uma questão de vontade pessoal, desejo de aprender etc., 
mas sim uma questão de sentido pedagógico. Esse sentido não estava claro nem para os alunos, nem para os professores (PROFESSOR B).

As alunas, através do grupo focal, apontaram também que na construção do Projeto cada aluno tem um papel fundamental, uma vez que as tarefas são divididas entre todos os participantes. Um grupo faz as pesquisas, outro grupo uma oficina, outro realiza um teatro sobre a temática. Observou-se nos relatos um tom de satisfação, quando as mesmas nos explicaram como o projeto tomou dimensões que elas mesmas não imaginavam: [...] uma apresentava a respiração, outra uma ginástica, então quer dizer, todas tivemos que falar, em público, então quer dizer participou todo mundo (ALUNA D).

Assim, pode-se considerar como aspecto relevante do trabalho com o Projeto a possibilidade de desenvolvimento do trabalho em grupo, provocando nos alunos a responsabilidade, o senso de trabalho coletivo, o companheirismo, o respeito mútuo, a aprendizagem de coordenação, a liderança participativa e a busca de soluções coletivas, o que implica "crescimento pessoal, coletivo, desenvolvimento de atitudes e valores em cada aluno" (PEDAGOGA A).

A empolgação nas falas também demonstrou como é importante que se acredite no sujeito educando enquanto sujeito de conhecimento, especialmente no trabalho com os jovens e adultos. Essa é uma forma de promover sua valorização e partir do que ela já sabe para a construção de novos conhecimentos: "[...] nós apresentamos nosso teatro em seminários, foi muito legal. A professora convidava a gente, ela queria que o projeto continuasse, que a gente levasse adiante [...]" (ALUNA F). Essa proposta representa também uma porta para o desenvolvimento de ações que promovam a formação integral dos sujeitos a qual considere mais do que a transferência dos conteúdos, ou seja, a formação cidadã crítica, participativa e coletiva: Desafio que se coloca ao projeto integrador como um componente curricular que
busque contribuir na formação integral dos alunos, contribuindo para a formação
de um aluno que tenha em sua formação profissional a dimensão da criticidade e
consciência cidadã. Nesse sentido, o trabalho com projetos desenvolvido pelo
PROEJA tem efetivamente um papel fundamental na formação profissional e
cidadã dos alunos do Proeja (PEDAGOGA A).

No desenvolvimento do Projeto, as alunas apontaram também como ponto forte o envolvimento dos professores que sempre buscaram se organizar de forma a colaborar com as atividades desenvolvidas pelos alunos. O que corrobora para a afirmação de Ferreira et al. $(2007$, p. 7):

\begin{abstract}
Os docentes envolvidos valeram-se de sua habilidade e experiência para propiciar, de acordo com a especificidade de sua disciplina, atividades diferenciadas que objetivavam a construção do conhecimento do aluno como partícipe e não como mero expectador no processo pedagógico. Nesse contexto, objetivava-se estabelecer uma relação reflexiva que permeava as bases científicas, históricoculturais e sociais.
\end{abstract}

Contudo, ao se dialogar com os professores que ministraram a disciplina de Metodologia, constatouse que no envolvimento dos professores houve falhas como, por exemplo, um maior envolvimento dos profissionais da formação geral em oposição aos professores da área técnica ${ }^{9}$, mais um reflexo da necessidade de ruptura do imaginário cristalizado da educação tradicional que domina o pensamento dos professores da área técnica e que resulta nessa resistência:

\footnotetext{
${ }^{9}$ Distinção que é feita no Instituto em relação aos professores que ministram disciplinas do núcleo comum e do núcleo profissionalizante.
} 
Talvez por terem participado da elaboração da proposta do Projeto Integrador, os professores da formação geral facilitam, atendem e se envolvem com o mesmo. Alguns mais e, outros menos, porém todos são unânimes em apoiar o projeto. 0 mesmo não acontece com a área técnica, principalmente no formato do projeto quando desenvolvido ainda na área de formação geral. Para esses, a validade é pouca e nada agrega em termos de conhecimentos, uma vez que os alunos ainda carecem de informações técnicas (PROFESSOR A).

No último momento, propôs-se às alunas que avaliassem o curso, a partir do percurso que desenvolveram no Proeja. As falas refletiram a necessidade de rompimento de estigmas com relação à EJA e à falsa ideia de que sua oferta na Instituição pode ameaçar à tradição de excelência da escola (CEZARINO E OLIVEIRA, 2008, p.15), como se pôde analisar a partir das falas das alunas: "[...] assim eu acho que a vinda do Proeja pra escola técnica, foi assim um passo de humanização, na minha percepção" (ALUNA A) e: "Depois que veio o Proeja pra esse colégio, a escola ficou humana, por que antes a escola era só minério... agora não, agora você tem dona de casa aqui, tem pai de família" (ALUNA B). Além de avaliar o Proeja as falas também apresentaram um tom de preocupação, com relação à forma de ingresso dos estudantes no Proeja, como também de revelar as ansiedades das estudantes com relação à inserção no mercado de trabalho, conforme depoimentos abaixo:

Quando eu entrei no Proeja aqui, era um Proeja, você tinha pessoas de dezoito, era uma sala bem equilibrada, nem gente muita velho, nem gente muito novo, hoje você olha pro Proeja que tá entrando aqui, são pessoas que já tem universidade, são pessoas bem mais novas (ALUNA F).

[...] igual tem uma menina que tá fazendo Proeja, vai tentar uma vaga de estágio comigo, é claro que eles vão pegar ela, ela tá com a cara mais nova.... com certeza vão falar assim: vou pegar uma de trinta, quarenta por que é Proeja? Vou pegar uma de vinte e cinco, vinte quatro que é Proeja também (ALUNA G).

Apontam a necessidade de consolidação de ações de encaminhamento aos estágio/emprego para o público Proeja, direcionando este público ao mercado de trabalho para romper na sociedade a ideia de que os alunos oriundos da EJA são menos qualificados.

Percebeu-se no desenvolvimento deste trabalho que, embora muitas dificuldades ocorram no percurso do Projeto Integrador, há que se reconhecer sua relevância, apontada nas falas dos professores, pedagogas e alunos, na formação integral do ser humano enquanto ser autônomo, ativo e colaborativo além de se apresentar como uma importante estratégia de aprendizagem.

\section{CONSIDERAÇÕES FINAIS}

Com a realização deste trabalho, pode-se considerar que os desafios postos ao aluno do Proeja têm início antes mesmo de sua entrada na instituição. Centram-se principalmente na dificuldade de acesso e na pouca disponibilização de informações sobre os Cursos Técnicos ofertados na modalidade EJA. Essas questões sugerem iniciativas no sentido de dar conta da necessidade de uma maior divulgação dos cursos em classes escolares de EJA, nos meios de comunicação e nas comunidades populares.

A tradição elitista desenvolvida dentro da escola e o imaginário que se faz sobre o aluno do Proeja refletem-se no comportamento dos servidores e alunos (dos cursos que não são ofertados via Proeja), gerando falas e posturas preconceituosas que negam o direito à EJA na sua plenitude. São 
elementos que marcaram as vivências das alunas da turma 2007/01, do curso de Segurança do Trabalho na Modalidade Proeja do Ifes e que refletem algumas necessidades, tais como: reformular a concepção de educação da instituição, investir na formação de professores para atuar na modalidade, desenvolver atividades de integração entre os alunos para, assim, caminhar para o rompimento do imaginário tradicional e elitista que tem marcado a educação no Instituto.

As vivências proporcionadas no desenvolvimento do Projeto Integrador, e os olhares produzidos a partir deste, levam a reafirmar a necessidade da valorização e do reconhecimento dos sujeitos e dos saberes por eles produzidos, como ferramenta que auxiliará no processo educativo dos sujeitos jovens e adultos. É uma forma de possibilitar um protagonismo que leva ao envolvimento do educando no seu processo de aprendizagem, além de fazer emergir elementos trazidos de suas experiências de vida.

O trabalho com o Projeto Integrador traz para o centro do debate a formação humana, já que prioriza o desenvolvimento de aprendizagens em detrimento do ensino conteudista, contribuindo para o desenvolvimento de práticas, de valores, de ações democráticas e de responsabilidade social, uma vez que a maioria dos projetos desenvolvidos busca solucionar problemas vividos cotidianamente pelos alunos, apontando assim, para o caminho da formação integral dos sujeitos: crítica, cidadã, participativa e coletiva. Não obstante, pode também contribuir para a superação da educação pautada no "libertar-reprimir".

Pode-se apontar, portanto, que a experiência do trabalho com Projeto Integrador configura-se uma prática pedagógica positiva aos alunos, aos quais é possibilitada uma vivência escolar que contribui para seu desenvolvimento social, fazendo com que se percebam parte de uma comunidade e como tal agentes possíveis de intervir sobre a mesma.

\section{REFERÊNCIAS}

ARROYO, Miguel Gonzáles. Educação de Jovens e Adultos: um campo de direitos e de responsabilidade pública. In.: SOARES, Leôncio; GIOVANETTI, Maria Amélia; GOMES, Nilma Lino (org`s). Diálogos na Educação de Jovens e Adultos. São Paulo: Ed. Autentica, 2005.

ARROYO, Miguel Gonzáles. O direito do trabalhador a educação. In: Trabalho e conhecimento: Dilemas na educação do trabalhador. São Paulo: Ed. Cortez, 2004.

BRASIL. Documento Base. Programa Nacional de Integração da Educação Profissional com a educação Básica na modalidade de Educação de Jovens e Adultos - PROEJA. 2007.

CENTRO federal de educaÇÃo TeCnOlógICA do ESPIRITO SANTO. Projeto Pedagógico Ensino Médio para Jovens e Adultos. Vitória: CEFET - ES, 2005.

CEZARINO, Karla Ribeiro de Assis; OLIVEIRA, Edna Castro de. Os sentidos do proeja: possibilidades e impasses na produção de um novo campo de conhecimento na formação de professores. ANPED. Anais...Caxambu, MG: 2008.2 Disponível em: http://www.anped.org.br/reunioes/31ra/1trabalho/GT18-4782--Int.pdf. Acesso em 24 de julho de 2010.

DOCUMENTO FINAL DO SEMINÁRIO NACIONAL DA EDUCAÇÃO DE JOVENS E ADULTOS. In: PAIVA, Jane; MACHADO, Maria Margarida; IRELAND, Timothy. Educação de Jovens e Adultos: uma memória contemporânea. UNESCO, MEC, 1996.

FERREIRA, E. B.; RAGGI, D. e RESENDE, M. J. A EJA integrada a educação profissional no CEFET: avanços e contradições. In: 30A. REUNIÃO ANUAL DA ANPED. Anais... Caxambu, MG: ANPED. 
Disponivel em: http://www.anped.org.br/reunioes/30ra/trabalhos/GT09-3196--Int.pd]. Acesso em: 28 ago. 2009, 2007. Tirar o grifado.

FERREIRA, Maria José de Resende. Escolarização e gênero feminino: Um estudo de caso no EMJAT/CEFETES. Monografia (especialização Latu sensu) Diretoria de Pesquisa e Pós-Graduação, Gerência de Pós-Graduação, Centro Federal de Educação Tecnológica do Espírito Santo. Vitória-ES, 2007.

FREITAS, Rony Cláudio de Oliveira. Produções colaborativas de professores de matemática para um currículo integrado do PROEJA - IFES. Tese (Doutorado em educação), Programa de Pós-graduação em Educação, Centro de Educação, Universidade Federal do Espírito Santo. Brasil, 2010.

FREIRE, Paulo. Pedagogia do Oprimido. 36. Ed. Rio de Janeiro: Ed. Paz e Terra, 2003.

GONDIM, Sônia Maria Guedes. Grupos focais como técnica de investigação qualitativa: desafios metodológicos. Universidade Federal da Bahia. Disponível em http://www.scielo.br/pdf/paideia/v12n24/04.pdf. Acessado em 07 de julho de 2010.

OLIVEIRA, Maria da Glória Medice de. O Cefetes Como Não-Lugar: Limites e possibilidades na inclusão dos alunos do Proeja nos cursos técnicos de Edificações e Metalurgia e Materiais. Monografia (especialização Latu sensu) Pós-graduação lato sensu no Programa em Educação Profissional Técnica integrada à Educação Básica na modalidade de Educação de Jovens e Adultos, Centro Federal de Educação Tecnológica do Espírito Santo. Vitória-ES, 2008.

OLIVEIRA, Marte Kohl de. Jovens e Adultos como sujeitos de conhecimentos e de aprendizagens. In: RIBEIRO, Vara Marsagão. Educação de jovens e adultos: Novos leitores, novas leituras. Mercado das Letras; São Paulo: Ação Educativa, 2001.

PAIVA, Jane. Tramando sentidos para redizer o direito à educação de jovens e adultos. Revista Brasileira de Educação, n. 30, jan./abr., 2006.

RAGGI, Desiree Gonçalves. A metodologia de projetos: uma possibilidade para a educação emancipatoria dos estudantes do EMJAT/PROEJA no CEFETES. Tese (doutorado) Faculdad de Estudios de Postgrado, Universidade Del Norte. Paraguai, 2008.

SILVA, Suir Martins da. O Proeja do CEFETES/Vitória: Dificuldades de acesso. Monografia (especialização Latu sensu) Programa de Pós Graduação em Educação, Centro Federal de Educação Tecnológica do Espírito Santo. Vitória - ES, 2007. 
